\title{
Dialogue 5: Financing for development in transition and beyond ODA
}

Official Development Assistance is first and foremost the financial basis for providing development cooperation from one country to another; either directly in the form of financial cooperation, or as an indirect investment in the form of technical cooperation. Even if countries graduating from ODA have concerns that go beyond financial support, the topic of ODA graduation is deeply interwoven with various questions relating to financing for development (FfD). Processes of graduation and transition must be embedded in international and domestic economic and financial systems, including capital markets and global governance structures. In this regard, the Addis Ababa Action Agenda ${ }^{91}$ (AAAA) provides a framework for financing sustainable development and serves as a central reference point. Its key elements include mobilising more and "better" domestic resources in developing countries, promoting foreign direct investment for sustainable economic growth, stabilising international trade as a driver of development, increasing funds for development cooperation, and reforming global debt financing and the international financial architecture. The AAAA confirms the complementary and catalytic role played by ODA and calls for better coordination with and alignment to developing countries' own strategies.

In that respect, both the Addis Agenda and the debate on transition and graduation ${ }^{92}$ try to look beyond ODA and emphasise new sources of financing and modalities of support: official and private, national and international, financial and non-financial. In our discussion, we try to link these two dots. While the graduation process raises questions on adequate measurement and categories of development, the FfD debate discusses reforms needed to lead the world to more stable economic and financial systems that foster development and are resilient to crisis. These issues are highly interrelated - in the end, both sides

91 The AAAA is the outcome of the Third International Conference on Financing for Development, held in Addis Ababa in July 2015, and a follow-up to the 2002 Monterrey Consensus and the 2008 Doha Declaration. As one critical foundation of the implementation of the 2030 Agenda and its Sustainable Development Goals (SDGs), it provided a new global framework for financing sustainable development by aligning all financing flows and policies with economic, social and environmental priorities.

92 See also the contribution on Transition Finance by Cecilia Piemonte and Olivier Cattaneo (OECD) in this publication. 
want to make sure that every country has access to the funds and means needed to make its way to a more sustainable development path - but the connection between them has not been sufficiently explored so far. We ask: what are the current trends and challenges in financing for development that are directly related to graduation and transition processes? Which financing tools are needed for the implementation of SDGs to succeed and what is the role of ODA in that? Specifically, what needs to be done regarding the increasing debt problem? Which systemic issues arise in a 'beyond ODA' setting and how does the system of financing international cooperation for sustainable development need to change? In particular, what is the role of multilateral, regional and national development banks?

The discussion was held between Fanwell Bokosi, Executive Director of the African Forum and Network on Debt and Development (AFRODAD), and Shari Spiegel, Chief of the Policy Analysis and Development Branch in the Financing for Sustainable Development Office of the UN's Department of Economic and Social Affairs (UN-DESA). It was facilitated by Ana Kemlein, a policy advisor on Financing for Development at GIZ's Department for Sectoral and Global Programmes, and Juliane Kolsdorf, editor of this publication. ${ }^{93}$

As regards the implementation efforts of the Addis Agenda on the ground, we are witnessing vibrant moments within the history of FfD. Nevertheless, the last Financing for Sustainable Development Report (FSDR) ${ }^{94}$ was a clear and desperate call for action: it seems that, on the global level, there is very limited progress related to critical and systemic issues of the agenda. Let us begin with the national level. Fanwell, what do countries need to finance their development goals and succeed in implementing the SDGs? Which tools and what kind of support? How should this support and these tools be governed? And, connecting it with the other dot, what is the role of ODA in this?

Fanwell Bokosi: If you look at the African Union's Agenda 2063, the African blueprint for development, and then at the UN's 2030 Agenda, you see that there are many similarities. While I will focus more on Agenda 2063, of course taking the bias that I am African, I conclude that some of these things are relevant for both agendas. First of all, one of the key issues that was identified in Africa in terms of spurring development is infrastructure development in order to connect people from one place to the other. If you look at these huge programmes for infrastructure development in Africa, you will see that aid does

93 For better distinction from the discussants, the inputs and questions by the facilitators are displayed in italic without naming the respective person.

94 The Financing for Sustainable Development Report was produced by the Interagency Task Force on Financing for Development. See United Nations 2019. 
not form much part of that. Countries have been looking beyond aid to find other means of financing infrastructure.

The second thing regarding development finance beyond aid is that, over the last five years, a lot of African countries have issued bonds on the international market, therefore in foreign currencies. They have used this to develop their finances in order to fund development. This has implications, and some of these countries have got into difficulty when the bonds reach maturity: they do not have enough funds to pay and then they go and borrow again. And every time they borrow again, or they default on payments, the interest rates get higher. So, African countries have resorted to the bond market, which is an actual increase in debt, but they are also still borrowing from the international market. The debt levels on the continent are getting close to what they were before the HIPC and MDRI initiatives ${ }^{95}$.

When you look at the debt statistics in terms of where Africans are getting their money for development from, first you will notice that concessional loans are becoming a smaller proportion of the total external debt stock of African countries. Most of the debt today comes from private sources and the interest rates are much higher. Second, the proportion of private traders or private creditors is increasing. Third, many African countries are getting a large share of loans to finance their development from non-traditional donors, especially China. I mention this because the way you handle these loans, including transparency and accountability, are different from, for example, the OECD DAC and the Paris Club, and that has become a very important issue.

In addition, many African countries are trying to enhance their domestic resource mobilisation. Their tax levels have increased, even though they have not gone to the level that you would want for development. However, because of the nature of African economies in terms of the composition of the labour market as regards informal vs. formal and unemployed vs. employed, they have tended to use taxation instruments that are characterised by 'easier to collect' rather than 'more valuable'. VAT is popular in that regard because it is easier to collect than taxing the companies. That means that a lot of big companies still have the advantage that governments are not aiming at them and, moreover, they are able to negotiate tax incentives in order to not pay enough taxes. I do

95 The Heavily Indebted Poor Countries (HIPC) Initiative and the related Multilateral Debt Relief Initiative (MDRI) are structured programmes run by the IMF and the World Bank to ensure that the poorest countries in the world are not overwhelmed by unmanageable or unsustainable debt burdens. To date, 36 countries -30 of them in Africa - have received the full amount of debt relief for which they were eligible through the HIPC and MDRI.

See: https://www.worldbank.org/en/topic/debt/brief/hipc (15.04.2020). 
not like the word 'fair share' because 'fair' is very subjective, but in these cases, you can ask if companies should not take more responsibility.

Finally, it is important to notice that corruption is also an issue that we have to worry about when considering the financing of sustainable development in Africa. There still is a high degree of illicit financial flows getting out of the continent. So, to conclude, you see that there are several big issues that we have to look at in an environment in which ODA is getting reduced.

With regard to the reduction of ODA, we should also take into account that we are facing an environment where a lot of European countries are now linking aid to capping migration. That could be a very big problem in the sense that some of the smaller countries that really need aid - like Lesotho for example are not at the forefront of capping immigration to Europe. We see that aid is being diverted to countries like Morocco or Libya, where migrants are closer to getting into Europe. This link is important. On top, under ODA regulations donors can count aid that is spent on in-country activities for refugees. That will inflate their ODA numbers, but fewer amounts of money will be transferred to support actual development for the people on the continent. So, that requires us to look beyond aid to see how we can actually best develop the continent.

Shari, could you complete this picture with some remarks related to ODA and transition processes, and connect it with current developments on the future of development finance, also within the FfD process?

Shari Spiegel: The underlying premise of the Addis Ababa Action Agenda is that financing development is not just about finance or money. It is about growth and the developmental process in countries, about national and international policies and policy frameworks.

Different strands of finance are meant to be used where they are most appropriate on the country level. For instance, public finance and private finance have very different roles. There are sometimes discussions on comparing ODA with private financing. People claim that there is an enormous gap that ODA cannot fill, and therefore we need private financing. Coming from within the FfD discourse, we tend to look at it very differently: ODA was never meant to fill some infrastructure gaps, such as investment in energy infrastructure. That is not its role. Private finance is most appropriate in certain circumstances when there are financial returns associated with investments. It is important to better understand the role of different financing flows in the process.

What does that mean in the context of transition? In this year's FSD Report, we look very closely at some of the graduation issues, and we differentiate between three different contexts: one is graduation from LDC status, another is graduation from low income to middle income, and the third is at the top, graduation from middle income to high income, which implies the loss of ODA 
eligibility. We find that there is a question of a 'missing middle'. That means that countries, as they move up from one context to another, lose access to certain sources of financing. We find that in about half the countries that move from low income to middle income there is a financing gap. This is not necessarily because ODA is falling. ODA generally increases when countries' per capita income rises above the low-income threshold, and only falls when countries reach upper-middle-income or high-income country levels. Nonetheless, ODA falls as a percentage of GDP as countries' incomes grow. Even though tax revenues rise in per capita terms, total public finance as a percentage of GDP declines so that it is unable to compensate for growing financing needs.

The implication of that is, as Fanwell said, some countries then go to the capital markets to cover their financial gap. The result is that the cost of financing goes up and the maturity of financing goes down. This is one of the reasons why there is this link to debt sustainability issues: it is based on both the size of the debt and the type of debt that is financing the gap. Therefore, the debt issue is one of the really big issues that we are discussing in the context of financing for development, including the question of whether we have the appropriate instruments to help countries in need.

One of the risks of borrowing on capital markets is that the debt is in foreign currency. If you have to repay debt in a foreign currency when most of your revenues are in your domestic currency, a currency devaluation can lead to serious debt problems. This risk can also apply to concessional loans and ODA when the loans are in foreign currencies. In the long run it is important to build local capital markets to be able to finance investment in local currencies. However, it is not so easy to balance these long-term planning processes with shortterm needs for investment.

We also need to look at the roles of development banks. Non-concessional long-term affordable finance can help countries fill financing gaps. There is the question of what concessionality means. Even non-concessional international public debt is still concessional compared to market debt as it is generally significantly cheaper than market debt and longer in duration.

The second set of questions being discussed is about what the role of ODA should be in terms of leveraging private finance. ODA has always played an important role in catalysing private and other sources of finance, including raising taxation through capacity development and incentivizing private investment by creating the enabling environment for private investment. More recently, there has been a greater focus on how ODA can directly leverage private finance, and in what situations such blended finance would be the most appropriate, effective sustainable financing source, without overcompensating the private sector. 
Finally, country ownership is important. There is the question of how to link foreign support, including for blended finance, with the priorities of the country. There is the new effort of developing 'integrated national financing frameworks'. The idea is that countries have a strategic plan that integrates all their financing flows and their financing priorities to support the implementation of their sustainable development goals. That could be a tool with which they can articulate their priorities better to their donors so that ODA can be better aligned with country priorities.

Let us dive further into some of your points. Fanwell, you underlined the different kinds of financial flows that are crucial on the national level for sustainable development, and ODA did not seem to be very important in that regard. What is it that makes ODA still effective? If it has any role, what is it?

Fanwell Bokosi: From my experience on the continent, speaking to a number of activists and government representatives, ODA is still important. Maybe that is why every time you go to a meeting of African finance ministers, they still insist on ODA and the 0.7 per cent of GNI as a commitment. This is the realisation that despite negative experiences in most African countries, ODA has played a number of positive roles, especially in the provision of public goods that do not have an outright or immediate market return. I will give an example: If you want to build a university and you do not have enough money, it is very difficult to entice the private sector to invest in such an undertaking in some African countries. So, ODA can be effective if it is put into areas that are catalytic, where it can serve as an investment. If you invest in education and health, thereby in the human capital of the country, and then if that human capital increases, if the health of the people increases, it sparks private activities. As Shari said, we need to understand what type of development requires what type of funding. This is why a lot of people are talking about GDP and about catalysing the private sector. We need to understand which types of projects can entice the private sector to invest, where they have a return even though they provide a public good. This is extremely important so that you do not end up with a scenario where the private sector comes in, makes all the profit and then leaves, while the people bear the risk. So, to conclude, there are different types of activities that need different types of financing.

In addition, ODA, as has been said, can play an important role in setting the fundamentals right. It is like you are setting the foundations to spring from for development. So, if most of the ODA is not used to actually solve problems, like if ODA is used for humanitarian projects which do not solve a problem, that does not spark other things. It might not be the best way to use it. I am not saying humanitarian aid is not important. I am saying that if we have to move away from aid, then ODA should be used in those public sector areas where the 
private sector cannot or does not go but which are still very important for the productive capacities of those countries to go forward.

Could you go more deeply into the specific needs of countries moving from middle income to high income, the challenges they are facing and also the role that ODA can play in that context? Also, to both of you: what could be the role for multilateral development banks in that specific setting, given for instance that their graduation criteria are different from that of ODA? Moreover, if we are moving beyond aid: how does the system of international cooperation and financing for development need to change in that respect? What do we need to do better regarding ODA?

Fanwell Bokosi: Indeed, looking at the African countries that are not classified, such as LDCs like Botswana and South Africa, or even Ghana and Zambia, that are moving towards the lower-middle-income category, their problems are slightly different. For example, in Botswana, you are not talking about the bare minimum level of income for people, but rather about the gaps in opportunity. First, the problems are more about income and inequalities rather than about absolute poverty, and it is also about the effect of these inequalities. The second thing is just the sheer numbers because you talk about the average. The average income for graduation is 12,000 US dollars. But when you look at the inequality issue, you might think about the people that are pulling that average up to 12,000 US dollars, and these are only the top ten per cent, whereas the absolute numbers of people in poverty are much higher, and their income is actually far, far below that threshold.

As these problems are slightly different, ODA in those countries will have to be crafted in a way that supports that particular context, which may be completely different from LDCs and other countries. So, it is important to look both at the absolute numbers in society and at the gaps between those that have and those that do not have, because, as Shari said, the pursuit of economic growth has come with increasing gaps in income and opportunities.

Shari Spiegel: First of all, I agree that inequality is an important issue. As we know, the largest number of poor people live in middle-income countries. In addition, every country has unique challenges, which means that policy responses will vary across countries. When resources are limited, understanding where the greatest bottlenecks are can help countries prioritise where financing would be most useful - what investments give the most bang for your buck, and have the largest impact.

Second, capacity development is very important. For example, in cases where the biggest challenge is in raising domestic resource mobilisation, capacity development in tax issues can be very important. The same applies to capacity-building in debt management. One of the issues that we have been 
surprised by is that, a large portion of the recent increase in borrowing has been in floating rate debt. Yet, with interest rates so low, it does not make sense for countries to be borrowing at floating rates that are likely to rise in the future. We are still in need of debt management capacity development.

A third issue that we have not yet discussed is how technology and digitalisation is changing the developmental model, what this means for countries, and if countries, both developed and developing, are ready for that transition. And again, it is really important to incorporate technology into planning and thinking forward, and capacity development.

And finally, we need to look into institution-building. The question should be: Where are the institutions weakest and what institutions need to be strengthened so that countries can be better prepared when they graduate, for example, to be able to build local financial and capital markets? The type of support may change before a country's transition so that the country's own institutions and its own internal structures are able to better support development after graduation. Part of that means, again, that there needs to be better and smarter planning in order to think about these complicated issues - especially given the uncertainty that comes with digitalisation changing the world, where nobody really knows what the impact is going to be.

As regards the role of multilateral development banks, MDBs, such as the World Bank and the regional development banks as well as some of the national development banks, including banks like KfW and others that operate across borders: MDBs can play an important role in direct investment, in catalysing private investment and in long-term lending to countries. The question of how to best leverage private investment and where it is most relevant is particularly complex in LDCs, though it can also be challenging in middle-income countries and in countries in transition. There are a lot of lessons to learn from past experiences, and we all need to be thinking about how to do that properly; and how to do that in ways which are both efficient and cost-effective and do not disturb private markets.

We could go into that in more depth, but before that, I would like to come to how the international system and cooperation needs to change and is already changing. We need to think more about vulnerabilities. Right now, graduation from ODA is based on income levels, but vulnerabilities are equally important and can push countries backwards. The question is: how does one bring vulnerabilities into the decision-making process, for instance vulnerability to climate but also to other external shocks? ODA is not the main or the only tool with which to address these problems; the international system, and particularly the IMF, aim to support countries that suffer from external shocks. Nevertheless, it is important to take vulnerabilities into account when it comes to understanding ODA graduation. 
You both criticised the measurement of the ODA category, both with respect to vulnerability issues and to absolute numbers versus average calculations. There are different measurements of development and of access to development finance. Where do you see the shortfalls and where do you see the need for changes in that respect?

Fanwell Bokosi: I think this is quite important. Coming from the African continent, we always said that these issues also affect European countries, but they did not want to listen. So, while Europe was developing and growing and everybody was talking about economic growth, no one thought that inequality could become an issue that would actually threaten the system. But if you look at the protests in Europe, the protests in the US and the far-right movements, it is all about frustration with the current economic system, which rewards only a few and leaves the majority behind, even though the average values are much higher. And I think that leads to a question about having to rethink the global model of development that we have. The advantage we have is that we are not talking about communism or central planning; we are talking about how to make sure that growth is not pursued for the interest of growth itself. And I think that is extremely important for countries that find themselves stepping up the ladder. I always give the example of a country like Zambia. If you went to Zambia a couple of years ago, everybody was celebrating the fact that Zambia had become a lower-middle income country, and everything was okay. Two years of drought followed this moment, then electricity problems and blackouts (because they did not have enough resources), then two years of inadequate rain, an energy crisis, and so on - and some of Zambia's gains were completely wiped out. This is one type of vulnerability, and of course there is climatic vulnerability. But it is not only that. Look at the example of Angola: a couple of years ago, we would never have talked about Angola being in financial crisis, but then oil prices went down. And because of a country's dependency on a few commodity prices and fluctuations in the commodity markets, you find it being vulnerable to these shifts. So, we need to look at the system and see how we pursue growth in a way that does not take growth as an end in itself but as a means to lifting up the majority of the people, as a means to human development. I think that is where we need to start tweaking the system. And when I hear the IMF and the World Bank talk about inequality these days, this is where I punch the air and say: Now we are talking! Because in the past, they kept saying that "trickling down happens very easily; do not worry, economic growth is going to increase and somehow the system is going to compensate the people at the bottom, and everybody is going to be better off." We are now realising that this did not exactly happen. I do not have a solution to how to 
tweak that, but I think we really need to think about new concepts when looking at the global economic system.

Shari Spiegel: I completely agree with that. I think that there are two elements that will come up: one is inequalities and the other are shocks. We are more focused on shocks because of the visibility of climate-related shocks. But there have actually always been shocks, and there have always been vulnerabilities that countries have faced. They are not only climate-related, but climate-related shocks bring our attention more to the questions of how to strengthen countries' systems, including their financial systems, and the importance of addressing vulnerabilities.

Talking about inequality, I think that neo-classical economists always believed this would not be a critical issue - you just redistribute; you maximise and then redistribute. In my view, there is now a much deeper understanding that, first, there is not always the political will to redistribute, and second, there are economic implications from inequality that go beyond simple redistribution. Today, these issues are being understood much better. While there has been enormous progress in analysis, inequality is still growing faster than the solutions.

Prior to the FfD conference in 2015 in Addis, the United Nations Intergovernmental Committee of Experts on Financing for Sustainable Development launched a report that was meant support the 2015 financing for development process. This report addressed the importance of including not just income, but also vulnerabilities and social needs in reflections on income graduation and the needs of countries. The idea was that by the time countries graduate in different processes, one area would have to compensate for the others. For instance, countries that are more vulnerable will have to be stronger in the other two areas to compensate for their vulnerabilities. For me, that is certainly something that must be thought of more broadly.

Today, the phenomenon of shocks is most noticed in relation to the small island developing countries and climate issues. Nevertheless, confronting the issue of vulnerability needs to go more deeply than that. We have already seen countries that graduate from one category into another and then backslide again. And we need to ask: What are possible solutions to this, particularly in terms of how to prepare better for shocks, and what types of instruments would be helpful in this respect? For instance, we looked at debt instruments. Some have been issued with hurricane clauses. More debt instruments should include clauses that allow for countries to delay debt payments during periods of shocks. In other words, risks are shared between the creditor and the debtor, as opposed to the debtor taking on all those risks. And especially when it is public debt, in the end, the creditors take these risks anyway due to the high risk of default during shocks. These types of structures would help make the process 
smoother when such events happen. We could also think more about incorporating other state contingencies into public debt. We know that there have been discussions about GDP-linked bonds in the private sector that have not taken off but if the public sector takes the lead, this could be a way to make these types of instruments more utilised. Insurance mechanisms can also help manage risks and be part of the solution, though it is important to understand their limitations. For insurance to work properly, you need diversification across countries, sectors and regions. The public sector can help enhance these sorts of mechanisms. There is a lot of space for thinking and ideas to help countries when shocks happen, as well as the implications of shocks on graduation.

We talked about 'what' needs to be done and you already started to talk about the 'how', sharing some solutions, for example regarding the debt challenge. Before we go more deeply into the development cooperation system, I would like to go back to the roots of the debt problem, dive a bit more into it and ask: What could be a better role for development cooperation in this debt challenge? Fanwell Bokosi: One of the things that we struggle with on the African continent is that we do not have an international debt resolution mechanism. A debt crisis is basically left between the creditor and the debtor. If the creditors are in a group like the Paris Club, then they can agree on solutions, because although the Paris Club is not a formal body, it does work together, and it actually helps. The problem is, as I said at the beginning, that more and more the Paris Club's importance - in terms of the volume and proportion of the aid that it has given to African countries - is getting smaller. As a result, it was much easier to deal with the MDRI and the HIPC processes, because most of that debt was owed to multilateral institutions and bilateral creditors, and either way, it was basically bilateral. It was also easier because this was public money; most of those bilateral donors lent money from their own taxpayers to African and Asian countries. That is why the Jubilee Movement ${ }^{96}$ was so successful, because the governments were able to forgive that debt based on their budgets. Compare that to the current scenario where most of the debt is private bonds: if a country issues a bond on the international market, the buyers are individuals who are buying into syndicates out of their savings. You are not going to go to the individuals and say: forgive the debts of the African countries because this could be their pensions, this could be their investment. As it stands now, we do not seem to have an international mechanism that can resolve that. And that might lead to a problem: if one creditor holds out, then the others cannot move; they cannot do in over 40 countries that called for major debt relief for poor countries by the year 2000 . 
anything else. So, I really think that we need some form of international mechanism to resolve debt.

The other thing is debt transparency. The problem with resolving this in the current international system is that we do not know who owes whom. Take the example of Germany and Zimbabwe. Germany was the largest bilateral creditor to Zimbabwe until China overtook it. Now, the German ambassador says: I do not know what Zimbabwe owes China. My problem is if I go to my government in Berlin and ask them to forgive the German debt of Zimbabwe, what if they ask me "are we just transferring resources so that Zimbabwe will be in a better position to repay Chinese debt?" In other words, even if I am willing to commit, I am just giving Zimbabwe fiscal space to repay another creditor. And if there is no transparency and if the Chinese are not talking to the Germans, then it is going to be difficult to resolve a future debt crisis.

Shari Spiegel: When we think about debt, there are three different areas. The first is that, even before they get to a debt crisis, highly indebted countries do not have the finances to be able to invest in the SDGs, despite the enormous financing gap in sustainable development. What can donor governments do to help those countries? One option could be debt swaps, and again, both the creditor and the debtor need to want to do this. In a debt swap, the borrowing countries shift from repaying the creditor to investing the money in the SDGs. Often people think about debt swaps in a crisis situation, but we should consider them more generally for countries that are heavily indebted. ECLAC has made a proposal for the Latin American region to do this through the Green Climate Fund. But whatever the mechanism, the first question would be: Are there cases where creditors agree to help heavily indebted countries swap some of their debt payment into SDG investments? There have been successful examples of debt swaps, sometimes with philanthropy buying commercial debt at discounted values and swapping it for investments.

A second area is to strengthen responsible borrowing and lending by both borrowers and creditors. This subject also relates to the Addis Agenda, which clearly states that debt is the responsibility of both the creditors and the borrowers. When creditors lend money, they make a decision. Interestingly, in private markets, creditors get paid an extra premium, a credit spread, for taking on higher credit risks. In the end, creditors are supposed to do credit screenings, so that if they lend to high-risk countries, they demand a higher return to compensate for the additional risk. If the country is unable to repay its debt and defaults on payments, creditors have to work with the debtor to restructure the debt. There have been many discussions about the principles of responsible borrowing and lending. Principles already exist, for example agreed by the G20, and others formulated by UNCTAD, but some of them have become controversial over time. The Addis Agenda calls on countries to devise a new set of principles 
for responsible borrowing and lending, to be agreed on a global basis, building on existing measures. Those principles would include issues of transparency, on both sides. However, it remains a question of whether the international community wants to pursue this at this point, or not.

The final area is debt resolution. As Fanwell said, we do not have a global system for sovereign debt resolution. In corporate debt, every country has its own bankruptcy regime, with clear legal rules that address the question of seniority - who is paid first when a company defaults. In sovereign debt, we do not have anything like that. It often happens that whoever has payments due first gets paid and whoever comes after that does not get paid. If someone has collateralised the debt, then they are going to be paid back and the other ones will not. Sovereign debt resolutions have recently become much more complicated as the creditor landscape has changed, and it is not clear if the methods used in the past (with various degrees of success) are going to work go forward. I am convinced that there is more willingness to approach these issues now from both creditors and from debtors, because there is a bigger realisation of how difficult resolutions are becoming.

If we look at the financial systems in a beyond-ODA context, the question about responsibility is crucial and needs to be debated a lot more. Who is in charge and who needs to take responsibility? This leads to the question of how the development cooperation system needs to change, and we have already touched on this matter. There is not much time left until 2030, we have a debt crisis on the horizon, and we are still working on long-term investment. We have different tools, but everything seems to still be in an initial phase where we are not really seeing an impact or success. So, what do we need to do urgently and how can we do it? Again, what is the role of ODA in this? What is the role of multilateral and national development banks, and if they should work together as a system, how may their governance have to change?

Shari Spiegel: There are several elements of the question. One issue on debt is how to differentiate how the funds being borrowing are used. When the investment associated with borrowing generates financial returns or leads to economic growth, the investment can help repay the debt. Yet, the impact of this type of borrowing is not always monitored, in part because governments don't have 'balance sheets' that account for both liabilities (i.e. the debt) and the assets (i.e. the investments). It is very challenging to incorporate this into the Debt Sustainability Analysis of the international financing institutions. That is where the development bank system can come into play. When regional and multilateral development banks lend for specific projects - as opposed to general sovereign lending - it is clear where the money is going. 
The second pillar is the national bank system: if a country has a strong national development bank that is financially sustainable, it can borrow against its own balance sheet. Such a development bank may not be as profitable as a commercial bank, nor should it be because it has a developmental mandate, but it should have sufficient returns to be financially sustainable. There are examples of very successful national development banks, such as KfW, though there are also examples failures. So, it's important for national banking systems to be well governed. For instance, there is a group in Africa that has come up with a set of principles, rules and guidelines on what good governance in national development banks should look like. I think that a lot more work could be done in that area, including questions on developing risk reporting for national development banks that takes into account their unique mandates. The International Development Finance Club (IDFC), the group of national development banks, brings some of the largest NDBs together, and can lead on some of these issues. In sum, we have to ask: How does the system enable countries to have more productive investments that can help generate growth and revenues to repay debt, and which do not hurt sustainability, but instead help that sustainability? Because right now, our system does not do this very well.

The second issue, in terms of development cooperation itself, is about loans, both concessional and non-concessional, and what their terms should be. Can there be changes today in the structure of loans, in government to government lending and in development cooperation lending? What would they look like? As we discussed, there are examples of state contingent debts. In the past, these loans have been structured in such a way that the borrowing country had to pay a bit more up in interest payments to get a guarantee for a future crisis. As a result, some borrowing countries are not interested in these types of loans, even though they might an efficient way to manage risks and help resolve crises. There needs to be more discussion between partners to see if there can be agreement on sharing this risk and how it can be done. As discussed, debt swaps are another mechanism to share risks. In the end, it comes down to one question: Are partners willing to work together to help countries that are heavily indebted today and need to invest in the SDGs, by finding some mechanism for them to be able to invest more?

In that respect, we also need to look into the modernisation of ODA. How debt relief is calculated in ODA has changed, and there may be a risk that this disincentivises debt relief in the future.

Fanwell Bokosi: One of the issues that already came up is: Why were we not worried about debt management? We did not worry about debt management because of the fundability of the debt. In other words, if these debts are coming from multilateral institutions or regional development banks, they are 'projectised'. You have a project, you get it approved, and there is some element of 
monitoring from the project provider. That is not the same with a bond. With a bond you raise the prospectus. But the prospectus is not binding. Once the money comes, you can use it for any reason that you want. And sometimes, for example in the case of Zambia, they wanted to raise a certain amount of money, so they issued a bond and it was over-subscribed. Suddenly, they had extra money that was not actually budgeted for, and you cannot really know how it was used. So, one way to deal with this issue is to start thinking about how ODA can empower citizens to hold their governments accountable in some of these highly technical areas. A lot of civil society organisations get involved in debt issues, but maybe ODA can help to improve that accountability, even in cases where the government gets money that is not 'projectised', like in bond markets. There is certainly a lot of corruption, a lot of actual theft of that money, because it is difficult to track. I would like to add a point about infrastructure. A lot of money is being given for infrastructure, but the question is: what type of infrastructure? I always give the example of Chinese aid. In a couple of African countries, we now have probably three more new football stadiums, each of which is empty all the time - well, the football teams are there, but most spectators cannot afford to go to the stadiums. Was that the right type of infrastructure to borrow money for? Who makes those decisions? So again, it is about accountability.

We have been talking a lot about financing for national development. Coming to the close of this interview, let us look a bit into the factor of global public goods. Many of the countries that are predicted to reach high-income status are important contributors in this respect. What do we need in terms of financing to ensure proper provision and protection of global public goods in a post- or beyond-ODA setting?

Fanwell Bokosi: This is why, for me, international development cooperation is extremely important, because no one country can actually deal with global public goods on its own. The issues of climate, the issues of other risks: you really need to have a mechanism that deals with all of those. The FfD forum is the place where you can discuss this; it is a place where you can start leading on these things and this is why we support the annual reviews (FSD reports, see above) produced by the FfD forum. As civil society organisations, we have always said that while we know that the technical expertise in some of these areas is at the OECD, it does not have the mandate and the legitimacy that the UN has. We know that the IMF has technical knowledge on some of these issues, but our aim is that the United Nations should continue to coordinate because, irrespective of the flaws of the UN system, it is the only place where people have equal power on most of the issues: one country, one vote. The other mechanisms of global development cooperation are not even close to that. We know 
that people talk about the ineffectiveness of the UN, and my argument is it is only ineffective because the big guys do not want to play by the rules. Because if everybody else agrees on the rules and only you as a country say no, then you undermine the system, you make it ineffective in order to blame it for not fulfilling its role.

Thus, I think that in terms of international cooperation, we need to support a rule-based system under the United Nations. I see movement in that direction towards a multipolar, a global governance system, and maybe that will help to begin to move the parts of the puzzle. Global goods can never be financed, can never be provided if we do not have proper international development cooperation, which, from my point of view, must be coordinated under some form of the UN system. They might not have the technical expertise, but they have specialised agencies; UNCTAD could be part of that coordinating role to move things forward.

Shari Spiegel: Even if this may be a pitch for ourselves: I completely agree that the UN has an important role and that the FfD forum is an important place to discuss these issues. Let me just add that, from my point of view, we have actually developed a lot of expertise in the UN on financing issues. In addition to that, the Inter-Agency Task Force on Financing for Development, led by the UN's Department of Economic and Social Affairs (UN-DESA), brings together more than $60 \mathrm{UN}$ and non-UN agencies, with a leading role for the IMF, the World Bank, WTO, UNCTAD and UNDP. In the FSDR, we bring together all this thinking and all the expertise from across the system on financing issues, including the OECD Secretariat, the Financial Stability Board and other financial standard-setting bodies. So, I do think that we have been building expertise, including learning lessons from across the international institutions over the past five years, on issues of financing for development. 